\title{
Evolution of Value Engineering to Automate Invention in Complex Technological Systems
}

\author{
Roy Woodhead ${ }^{*}$, Mohammed Ali Berawi² \\ ${ }^{1}$ Sheffield Business School, Sheffield Hallam University, 38-40 Howard Street, Sheffield, S1 1WB. UK \\ ${ }^{2}$ Department of Civil and Environmental Engineering, Faculty of Engineering, Universitas Indonesia, Kampus UI \\ Depok, Depok 16424, Indonesia
}

\begin{abstract}
Many global companies specializing in complex technological systems use forms of group decision making to select a combination of solutions from suppliers. This requires technical expertise and up-to-date awareness of what is available within and outside the company. The use of artificial intelligence seems like an obvious progression but is fraught with difficulties. As a step in this longer-term direction, this paper looks to a methodology that uses the idea of functionality to first list abstract requirements before finding potential solutions with appropriate performance characteristics. This paper re-examines a methodology called value engineering, which mixes measurable and immeasurable concepts in its foundational idea. This paper reasons and deduces a new way to conceive this foundational idea so that it can be modelled mathematically and provide a useful step toward a database ontology and schema that would suit artificial intelligence. It also provides an immediate benefit to value engineering practitioners in workshops.
\end{abstract}

Keywords: AI; Function; Functionality; Invention; Innovation; Value engineering

\section{Introduction}

This paper combines many years of industrial experience, understandings drawn from literature reviews, and a model that is reasoned. The purpose of the paper is to mark a starting point for further research built out of practice. It does this by developing a new method that will improve dialogue between manufacturers and customers. The paper has two aims: a longer-term aim that opens the way for artificial intelligence (AI) to be used and a short-term aim to produce a way that value engineering (VE) can better utilize cocreation.

While VE practice is still firmly rooted in the idea of group decision making and workshops, its foundational ideas hold the key to coordinating many aspects of an innovation management process in large technological systems. The successes of VE stands on the articulation of functionality in multidisciplinary teams within workshops (Kaufman, 1985), and this paper offers a new methodology that can aid practice.

This paper distinguishes the act of invention from the implementation of inventions, which is viewed as innovation (Tidd and Bessant, 2015). It will focus on invention and limit its scope to the production of credible ideas from experts that have yet to stand the test of adoption. 
What characterizes the complex technological systems this paper focuses on is that they integrate many component solutions made by suppliers. Often, there are so many possible options and combinations that it can overwhelm a team of multidisciplinary decision makers, especially as workshops are time constrained. Examples of component solutions made by suppliers could be high-speed railways (Berawi et al., 2015), railway operation and maintenance (Rahman et al., 2018), a plan for a smart city (Woodhead, 2018), or an airport design (Yuliawati et al., 2015). They eventually become choices requiring expert technical selection in some methodological framework.

\section{What is VE and why is it worth considering?}

This paper begins by critiquing VE (SAVE International, 2020a; 2020b) to rework this old invention methodology and build new theoretical foundations that enable new modes of practice. Based on industrial experience, the authors have seen large global corporations buy new equipment that they did not realize they already owned because idiosyncratic naming did not link to the needed functionality. For example, a former VE client of Dr Woodhead's, a leading global engineering firm in the UK, spent $£ 5$ million building a test rig when they already had one in the US that could do the same work. Similar situations for global companies were observed in practice, often due to inconsistent naming conventions across various countries.

A common factor facing large companies seems to be a metadata problem and how "things" are inconsistently named in databases. A thing's name and how it can be useful in a particular context are not always obvious. To give a concrete example, think of a chair being used to prop a door open. The chair was not designed for this use, but humans often see other properties in a thing so that they can make use of in inventive ways. It is unlikely that a description of a chair in a database would convey these additional properties, however, and so an algorithm searching a database would likely miss this possibility.

To make progress, this paper will focus on what is often seen as the distinguishing aspect of VE through a reworking of an old idea of function analysis (Miles, 1961; Bytheway, 2005; Kaufman and Woodhead, 2006) that links to a view of a relationship between value, function, and cost first put forward by Miles (1961).

i) $\quad$ Value $=$ Function $/$ Cost

Miles (1961) originally argued for a process that could span several weeks with internal engineers working on ways to do what was already done, but faster, better, and cheaper. Interestingly, this was not part of his later work, probably because a five-day workshop model had been established as the dominant delivery model by then (Miles, 1972; King, 2000).

At the heart of this initial version of VE (Miles, 1961) was a period of intense study by a team, typically engineers. This deeper enquiry as a group is a root cause of valuable multidisciplinary team learning and successes in early VE. However, what once took weeks is typically done in days now, some episodes in the UK construction industry not even taking a single day. This is a mistaken separation of the performance of a methodology from the act of meaningful team learning and development of penetrative insights.

However, VE as a practice has not really evolved its core theories to play a much more central role in digital innovation as it clings to an interventionist model in capital project lifecycles at stage gates. In the oil industry, a number of interventionist approaches at stage gates are also mandated, such as constructability studies collectively named "value improving practices" (McCuish, 2002; Hermanides et al., 2010). What is needed is a return to Miles' original views that focuses on team-based invention outside of processual, time- 
constrained workshops.

\subsection{The Core Idea of VE}

The seminal idea of Miles (1961) was Value = Function / Cost, which was later changed to Function / Resources. Even so, this adaptation has the same issues as its original form in that it mixes measurable (e.g., cost) and immeasurable (i.e., function) concepts.

For example, understanding that the function of a human heart is to pump blood enables the consideration of other mechanisms that can perform this function should the human heart fail, but to measure the heart's value is not easy. This paper adopts a pragmatic-realist perspective (Rescher, 1999) and so does not dismiss immeasurable concepts as would other philosophical stances. This does require more precision in what is meant when using the word "function."

\subsection{What is Meant by Function and Functionality?}

For Miles (1961), "All cost is for function." He built a logic that basically states that customers buy things because they "do something the customer desires," be that a mode of usefulness or a form of aesthetic beauty that causes delight.

When identifying a function within the practice of VE, Miles explains how it takes effort to peer through our superficial notions of things and ask, "what does it do?" Miles (1989, p. 25) explains that:

Intense concentration, even what appears to be overconcentration of mental work on these functions, forms the basis for unexpected steps of advancement of value in the product or service.

For Miles and many practitioners (e.g., Crum, 1971; Dell'Isola, 1982; Kelly and Male, 1991; Kaufman and Woodhead, 2006), the idea of function in VE is about some kind of action performed on some thing that becomes a requirement that requires a solution.

The required action is often named by a verb and the target of that action with a noun in a syntactical process that is intended to make people think more deeply and clearly about what exactly something does (See Figures 1 and 2). However, in practice, this can lead to a focus on syntax rather than functionality (Woodhead et al., 2004).

What clearly distinguishes VE from other innovation methodologies is this identification of functionality and the consideration of other ways to perform that functionality. This exploration of functionality attempts to look deeper than any superficial first impression to articulate a purpose, a raison d'etre, and the operational contribution that a part makes to the whole system it is within. This offers a way to link requirements to solution selection, as in Figure 1.

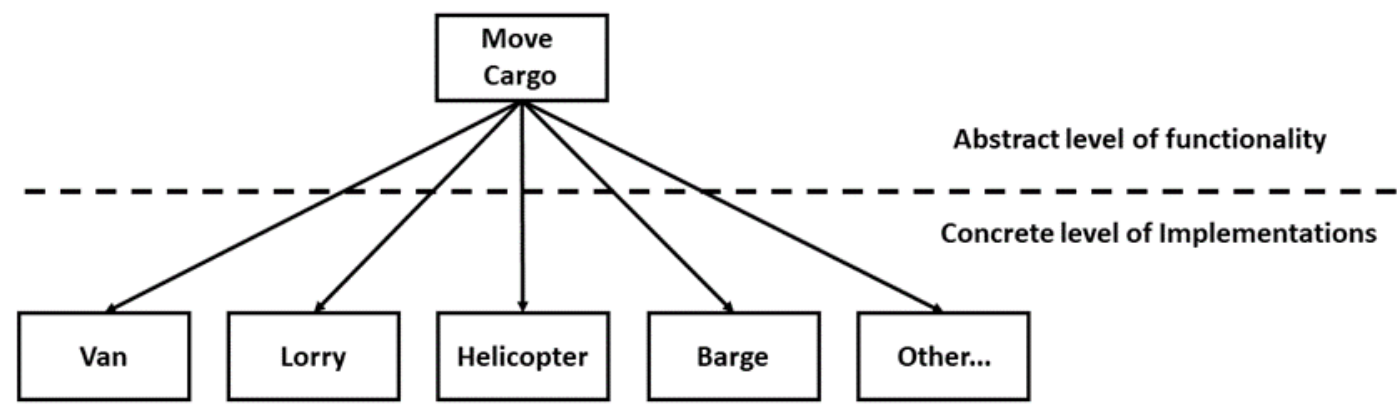

Figure 1 Abstract function and multiple ways to implement it

Figure 1 shows a simplistic example of a single needed function and multiple ways that could be chosen to perform that functionality. The key idea is the ability to separate the required intentionality from a list of concrete implementations so that the best one can be 
selected. The actual selection of what counts as "best" would be based on attributes such as time, cost, quality, and carbon footprint, in a specific context and from the perspective of a buyer.

For this paper, the context is some kind of technological ecosystem that comprises functionality to be performed and technology to perform it. This begs the question of what is meant by technology and why that is relevant to this discussion.

\subsection{What is Technology and How Does it Link to Functionality?}

The philosopher Ferré (1995) argues that technology is the "practical implementation of intelligence." This implies that technology is more than a device itself that comprises inanimate objects that operate to a design in order to create a form of usefulness or aesthetic. Consideration of Heidegger's (2001) view of technology reveals that it is about bringing something into existence. The act of conceiving the needed functionality and then inventing a way to perform it conceptually unifies as technology manifests. Searle (1995) argues something similar from the perspective of social constructivism when he explains that a coin can function as money and also as a screwdriver used to twist a screw out of wood, for example. The idea of functionality is independent of the solution used to perform it. First comes the required functionality, then comes the search for a way to perform that required functionality. Feenberg (2012) explores a number of perspectives of the relationship between our socially determined idea of functions in devices and a natural causality that allows those devices to work. He also points out that from a philosophy of technology perspective, this turns out to be a complicated discussion, and not all eminent philosophers in the field agree. Kroes (1998; 2009), another philosopher of technology, offers an epistemological and ontological view of functionality as part of physical structures. He sees the abstract idea of functionality but does not separate it from the idea of the real thing that possesses it. Seni (2005), on the other hand, holds an epistemological view that could separate these two ideas. Our view is closer to the epistemological view of Seni, which accepts the conceptual separation of functionality from ontological artifacts as key to invention in complex technological systems.

A problem in practice is a confusion as to whether functions, actions, or processes (Mahner and Bunge, 2001) are being considered, especially in time-constrained workshops. Berawi (2006) created a thought process that separated functions from real world actions or processes. For him, the sense of functionality is about an essential contribution to a system of other functions that collectively interoperate, such as the bodily function of a heart within a human body. This links the idea of function to an idea of effectiveness and purpose and provides a useful heuristic to select named functions to use as labels in the training of a neural network.

Functionality is a way of recognizing what a thing can do, such as using a chair to prop open a door. So, functions are epistemological insights into how ontological properties could be used in a method to achieve a desired outcome. As such, they are abstract requirements for empirical technologies.

\subsection{The Role of Solution Attributes and Properties}

Our longer-term idea is that if the attributes (i.e., features) of each potential solution to a key function (e.g., moving cargo) are known a priori then they can be stored in a database and selected by an AI algorithm to find the best choice from all options within a global enterprise. The user would simply enter performance characteristics for a function, and AI would find the best fit from the options stored within its database. The AI would be a type of recommendation system, and a Google search shows numerous tutorials.

During experiments with machine learning, a key issue was scarcity of data for a single 
function to train on, and so the Gaussian Naive Bayes classifier proved to be the best option. With more data, we expect different classifiers to outperform our initial findings.

The articulation of theories of functionality and the generation and selection of solutions to perform that functionality are typically done in a workshop environment in VE practice. These are usually multidisciplinary workshops. The building of functionality models, known in VE as FAST diagrams, has more relevance to those in the workshop as a process in which different disciplines gain shared insights into the way other disciplines see how things need to work in a complex technological system. The authors have access to the outputs of some historical workshops and are positive about our next steps toward using AI but also wary of how complex this challenge will be.

In workshops considering a common challenge, such as the design of an oil pipeline, the outputs can be dissimilar, suggesting that the act of conceptualization depends on the knowledge held in the heads of workshop participants. AI offers the potential to perform better by allowing forms of open innovation (Chesbrough, 2003), and knowledge not in the minds of participants, to be part of the invention process. This is seen as a worthy longerterm goal, but accepting this grand vision is far from our capability today.

This paper will now put aside its longer-term AI ambition and focus on overcoming the tendency of VE and the use of functionality to singularly head toward cost reduction. As above, a key issue is that the ideas of both value and needed functionality are subjectively identified by at least two key stakeholders. There is the producer who seeks the highest price for its wares and there is the buyer seeking to pay the minimum for them.

The actual price arrived at must be found at the point where both of these two stakeholders believe the number being quoted for the price is at an optimal point. It is viewed as a fair price by the producer for the effort of bringing the solution to the market. It is likewise viewed as a fair price by the buyer given its opportunity cost. The challenge is to create a workshop process that would enable this point to be found in a co-creation model (Ranjan and Read, 2019).

\subsection{Theoretical Framework}

The abstract concept of functionality allows a conceptualization that separates a pursuit of effectiveness (i.e., worthy goal achievement) and efficiency (i.e., optimal method).

Figure 1 shows an example of a named function and that multiple options exist to perform that function. As was explained, the choice of a specific solution is contextdependent and value-laden as it would compare factors such as cost, timeliness, and security from a particular perspective with vested interests.

VE holds a key to automated invention with AI because it yields an explanation of how to solve complex technological problems by identifying needed functionality and then considering different ways to perform that functionality. But first, its main criticism, that it only focuses on cost minimization, must be overcome so its potential can be seen.

\section{Methodology}

This paper relies on reasoning, deductions, and social constructivism that combine insights from the literature and over 30 years of experience of stimulating inventions and innovation in corporations and large capital projects. This has been pursued through an action science approach (Argyris, 1995; Kaplan, 1998; McNiff, 2017), grounded in practice, that sees the whole idea of scaling inventions to become innovations as an act of organizational learning (de Ven et al., 2008). It builds on this prior knowledge in order to deductively reason a new method that will help today's workshop-based practice as well as provide a starting point for an AI method later. 
As previously explained, current VE practice tends to place an emphasis on efficiency, and this is in part because its core formula can only measure cost and so assumes value and functionality. Here is the theoretical basis for change:

i. Functionality is a concept of required work to be done (i.e., a form of requirement).

ii. Functionality is achieved through the performance of measurable solutions.

iii. Measurable solutions can impact value in a context differently (e.g., one method more expensive than another).

iv. Effectiveness is a view based on the adequacy of named functionality to achieve a predefined desirable aim or outcome.

v. Efficiency is a view based on the cost of a solution and its translation into a price that customers would be willing to pay.

The question becomes, how can Miles' original idea (i.e. Value = Function $/$ Cost) be reworked to better handle the calculus between effectiveness and efficiency?

\section{Reworking the Numerator of Function to Become Functional Value}

For the numerator "Function," this paper proposes a change to "Functional Value." This is done to reflect that the manufacturer or producer identifies functions in the act of design. However, the manufacturer holds the assumption that all functions are necessary, or why would they include them? Customers need to test this assumption so that an idea of what the manufacturer believes is valuable can be compared to what customers think is valuable. This co-creative tension opens the door to numerous new approaches to designer and stakeholder dialogue.

For ease of explanation, imagine that just four functions (see Figure 2) have been identified by the designers, which they believe the customer, in this case a food kitchen for homeless people, will desire and which are necessary to make a system of all four functions work in an integrated fashion as a product or service.

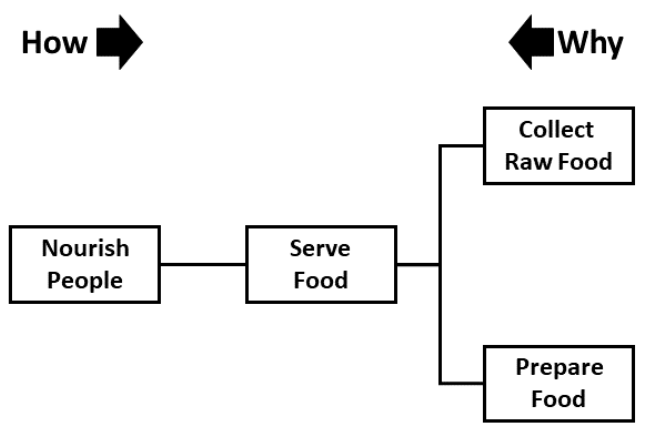

Figure 2 A system of functions representing the idea of functionality

Figure 2 makes explicit what has to be done without specifying how it is to be done. If there were four functions offered by the producer, then the same number of tokens (e.g. a way of recording a votes) could be allocated to customers that would pay for a solution. If the manufacturer's designers' view of necessary functions is valid, then, in theory, each customer would place one and only one token on each function (i.e., share them out evenly). However, if customers prefer one function more than another and allocate, say, two tokens to that function, then at least one function will show as not being valued. This is why the number of tokens given must be the same as the number of functions the design team believes are needed, so a gap may appear.

If a function receives zero tokens, then the design team should try to innovate its solution so that there is zero cost allocated to the delivery of the function that customers do 
not care about. It becomes a tool that allows designers and customers to use notions of value to shape the act of co-creation by calculating functional value.

This idea will be explored further. Imagine there are four different functionality models, each comprising four functions only. Figure 2 shows one for a food kitchen to nourish people, and now three additional cases are proposed for different problems, such as how to reduce carbon emissions, how to lift people out of poverty, or how to rethink universities.

For each of the functionality models, five customers, people that have consumed or are highly likely to consume the product or service, are asked to allocate four tokens each. In theory, each customer will spread his four tokens over the four functions equally as they are supposedly all necessary for the consumer in the eyes of the designer. This is shown in the first matrix below (see Figure 3). This is what the producer expects, and so all 20 cells (i.e., four functions $\times$ five customers) have a value in them out of 20 possible cells, yielding a functional value of $100 \%$ (i.e., $20 / 20=100 \%$ ).

\begin{tabular}{|c|c|c|c|c|}
\hline & \multicolumn{4}{|c|}{ Function } \\
\hline & A & B & C & D \\
\hline \multirow{5}{*}{$\begin{array}{l}1 \\
2 \\
3 \\
3 \\
3 \\
3\end{array}$} & 1 & 1 & 1 & 1 \\
\hline & 1 & 1 & 1 & 1 \\
\hline & 1 & 1 & 1 & 1 \\
\hline & 1 & 1 & 1 & 1 \\
\hline & 1 & 1 & 1 & 1 \\
\hline
\end{tabular}

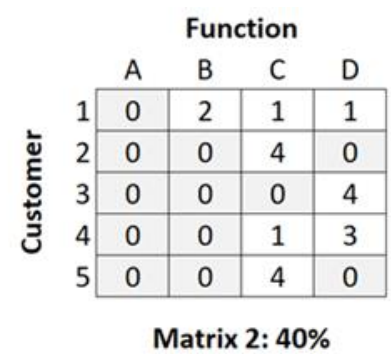

\begin{tabular}{|c|c|c|c|c|}
\hline & \multicolumn{4}{|c|}{ Function } \\
\hline & A & B & C & D \\
\hline \multirow{5}{*}{ 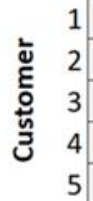 } & 0 & 4 & 0 & 0 \\
\hline & 0 & 4 & 0 & 0 \\
\hline & 0 & 4 & 0 & 0 \\
\hline & 0 & 4 & 0 & 0 \\
\hline & 0 & 4 & 0 & 0 \\
\hline
\end{tabular}

\begin{tabular}{|c|c|c|c|c|}
\hline \multirow{7}{*}{$\begin{array}{l}1 \\
2 \\
3 \\
4\end{array}$} & \multicolumn{4}{|c|}{ Function } \\
\hline & A & B & C & D \\
\hline & 0 & 0 & 0 & 0 \\
\hline & 0 & 0 & 0 & 0 \\
\hline & 0 & 0 & 0 & 0 \\
\hline & 0 & 0 & 0 & 0 \\
\hline & 0 & 0 & 0 & 0 \\
\hline
\end{tabular}

Figure 3 Only four functions considered by five customers

In the second matrix (see Figure 3), customers allocate tokens in different ways. This would tell the producer that there needs to be a deeper enquiry to understand why this inconsistent voting is happening. Customers might belong to different market segments with differing ideas of what counts as value, that are not understood. In Matrix 2 (see Figure 3 ), eight cells have numbers in them out of 20 , yielding a functional value of $40 \%$ (i.e. $8 / 20$ $=40 \%$ ).

In Matrix 3 (see Figure 3), customers agree that function B is the only one that is valuable to them, and they place all four tokens on $B$. The designers must now try to ensure minimal cost in delivering functions $A, C$, and D as customers do not value them, while also striving to enhance function B. This matrix has five cells with values in them out of a total of 20 and so yields a functional value of $25 \%(5 / 20=25 \%)$. Out of 20 possible tokens, customers do not see value in 15 of them.

Finally, Matrix 4 (see Figure 3) shows a potential failure for the manufacturer's design in which customers say that all functions have zero value for them.

This paper has now explained a method to calculate a value for the numerator and which can be used to simultaneously explore ways to increase or decrease value from both the producer and customer perspectives.

We can now show our numerator as follows:

ii)

$$
0 \% \leq \text { Functional Value } \leq 100 \%
$$

\subsection{Reworking the Denominator to Become the Probability of a Price}

The next challenge is to calculate a denominator that scales with the numerator. Price is chosen as the denominator rather than cost as it better aligns with the customers' view of value. This subtle change is important. As stated previously, Miles' seminal ideas were formed in an era of material shortages and a time when corporations had more economic 
power than consumers, as demand outstripped supply post-World-War-II (Goodman, 1995), so they focused more on their own internal efficiencies. Today, the opposite is the case, and fickle customers with internet-enabled market intelligence can find rival products much more easily than in Miles' time (Hilton, 2007; Labrecque et al., 2013).

The numerator is a percentage between $0 \%$ and $100 \%$. The denominator needs to be the same scale so that a ratio can be constructed that allows functionality and predicted price to work together to give some indication of value.

To achieve a denominator that is also a percentage that allows an association between the design price and rival offerings in the market, the Student T distribution will be used to find the cumulative probability of a price from a distribution of comparable prices for similar purchases of products or services or for shadow products or services.

Imagine that, from an internet search on a platform such as eBay or Alibaba, a product or service similar to what is being innovated has the following prices (in \$ AUD) that will set customer expectations: $\{\$ 24.50, \$ 26.20, \$ 28.60, \$ 29.70\}$.

The mean is $\$ 27.25$, and the standard deviation is $\$ 2.34$. The number $(\mathrm{n})$ in the sample is four and so $\sqrt{ } \mathrm{n}=2$. From this, the standard error is $\$ 2.34 / 2=1.17$

The $t$ score of interest is the price of our solution minus the mean price divided by the standard error. Say our solution is currently priced at $\$ 26.0$; then $(\$ 26.0-\$ 27.25) / 1.17$ gives a t score of -1.068 .

The cumulative distribution function can be used to find the probability of the $t$ score within a range from very cheap (i.e., $0 \%$ ) to very expensive (i.e., 100\%), for our price. What is of interest is the probability of our price point, which enables consideration of the likelihood that it would be acceptable to customers based on proximity to the mean price and customer expectations of functionality.

In Microsoft Excel, the built-in function used is T.DIST(t score, $(n-1), T R U E)$ for this task. The bracket with $\mathrm{n}-1$ is for the degrees of freedom. For our example, the input would be T.DIST $(-1.066,3, T R U E)=18.22 \%$

If a decision was made to price our product or service at exactly the mean price of $\$ 27.25$, so the cumulative distribution function would have been $50 \%$. This example shows that the planned price is on the low side of what customers might be expecting. This approach demonstrates a way to show the probability of price as the denominator.

\subsection{The New Theory of Modelling Value, Functionality, and Price}

This paper outlines an approach to modeling in a way that provides a logical consistency within a single decision space. To avoid confusing different definitions of value, the dependent variable will be named the value ratio. From Matrix 2 above (see Figure 3), the numerator is $40 \%$ and moving away from the perspective of cost to price (i.e., cost plus mark-up) that a customer will pay; the current price of $\$ 26.00$ has a cumulative probability of $18.22 \%$ of being expected.

The value ratio (VR) in this example is $40 \% / 18.22 \%=219.54 \%$.

If the manufacturer's designers now select alternative methods to perform the same functionality, they will arrive at a new cost (say $\$ 27.25$, which translates to a $50 \%$ probability of being expected by customers); this yields a VR of $80 \%$ (i.e., VR $=40 \% / 50 \%=$ $80 \%)$. They will see that this second option has less value than the previous option (219.54\% v 80.00\%) and be able to objectively disregard it as inferior.

What is more, all possible outcomes can be mapped by considering the ratio of all possible functional values from $0 \%$ to $100 \%$ over the cumulative probability of price from $0 \%$ to $100 \%$ which is shown in Table 1. 
Table 1 Value produced from a ratio of functional value to probability of price

\begin{tabular}{|c|c|c|c|c|c|c|c|c|c|c|c|c|}
\hline \multirow{11}{*}{ 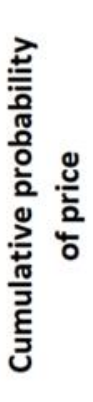 } & $100 \%$ & $1.0 \%$ & $10 \%$ & $20 \%$ & $30 \%$ & $40 \%$ & $50 \%$ & $60 \%$ & $70 \%$ & $80 \%$ & $90 \%$ & $100 \%$ \\
\hline & $90 \%$ & $1.1 \%$ & $11 \%$ & $22 \%$ & $33 \%$ & $44 \%$ & $56 \%$ & $67 \%$ & $78 \%$ & $89 \%$ & $100 \%$ & $111 \%$ \\
\hline & $80 \%$ & $1.3 \%$ & $13 \%$ & $25 \%$ & $38 \%$ & $50 \%$ & $63 \%$ & $75 \%$ & $88 \%$ & $100 \%$ & $113 \%$ & $125 \%$ \\
\hline & $70 \%$ & $1.4 \%$ & $14 \%$ & $29 \%$ & $43 \%$ & $57 \%$ & $71 \%$ & $86 \%$ & $100 \%$ & $114 \%$ & $129 \%$ & $143 \%$ \\
\hline & $60 \%$ & $1.7 \%$ & $17 \%$ & $33 \%$ & $50 \%$ & $67 \%$ & $83 \%$ & $100 \%$ & $117 \%$ & $133 \%$ & $150 \%$ & $167 \%$ \\
\hline & $50 \%$ & $2.0 \%$ & $20 \%$ & $40 \%$ & $60 \%$ & $80 \%$ & $100 \%$ & $120 \%$ & $140 \%$ & $160 \%$ & $180 \%$ & $200 \%$ \\
\hline & $40 \%$ & $2.5 \%$ & $25 \%$ & $50 \%$ & $75 \%$ & $100 \%$ & $125 \%$ & $150 \%$ & $175 \%$ & $200 \%$ & $225 \%$ & $250 \%$ \\
\hline & $30 \%$ & $3.3 \%$ & $33 \%$ & $67 \%$ & $100 \%$ & $133 \%$ & $167 \%$ & $200 \%$ & $233 \%$ & $267 \%$ & $300 \%$ & $333 \%$ \\
\hline & $20 \%$ & $5.0 \%$ & $50 \%$ & $100 \%$ & $150 \%$ & $200 \%$ & $250 \%$ & $300 \%$ & $350 \%$ & $400 \%$ & $450 \%$ & $500 \%$ \\
\hline & $10 \%$ & $10.0 \%$ & $100 \%$ & $200 \%$ & $300 \%$ & $400 \%$ & $500 \%$ & $600 \%$ & $700 \%$ & $800 \%$ & $900 \%$ & $1000 \%$ \\
\hline & $1 \%$ & $100.0 \%$ & $1000 \%$ & $2000 \%$ & $3000 \%$ & $4000 \%$ & $5000 \%$ & $6000 \%$ & $7000 \%$ & $8000 \%$ & $9000 \%$ & $10000 \%$ \\
\hline & & $1 \%$ & $10 \%$ & $20 \%$ & $30 \%$ & $40 \%$ & $50 \%$ & $60 \%$ & $70 \%$ & $80 \%$ & $90 \%$ & $100 \%$ \\
\hline
\end{tabular}

\section{Functional value}

In Table 1, if the functional value is held constant (e.g., 40\%), then consideration of different probable prices looking from bottom (1\% cumulative probability of price) to top $(100 \%$ cumulative probability of price) yields a trend as the prices rise for the same functionality. Then value decreases from $4,000 \%$ to $40 \%$.

If, on the other hand, the cumulative probability of the price is held constant (e.g., only consider the row for mean price, which has a cumulative probability of $50 \%$ ) and the functional value is changed (i.e., from left to right), then value rises from $2 \%$ to $200 \%$ as a solution would have more functionality that customers value for the same price.

This new approach, only to be used to compare similar complex systems, enables cocreation dialogues between customers and producers, where the formula aids meaningful discussion and innovation with conversations between stakeholders focused on value. For example, in the extraction of oil and gas from shale plays, does directional drilling or multiple slant wells offer the best value to the project? This could be determined as shown using the methodology above that builds on Figures 1, 2, and 3.

This new approach, called value, functionality, and price, combines ideas of value, functionality, and price in a way that aids complex technological projects comprising customers and different vendors:

iii) $\quad$ VR = functional value / cumulative probability of price

In an attempt to make this of more practical use, a matrix is shown below that outlines what various scores of a VR imply (see Matrix 1).

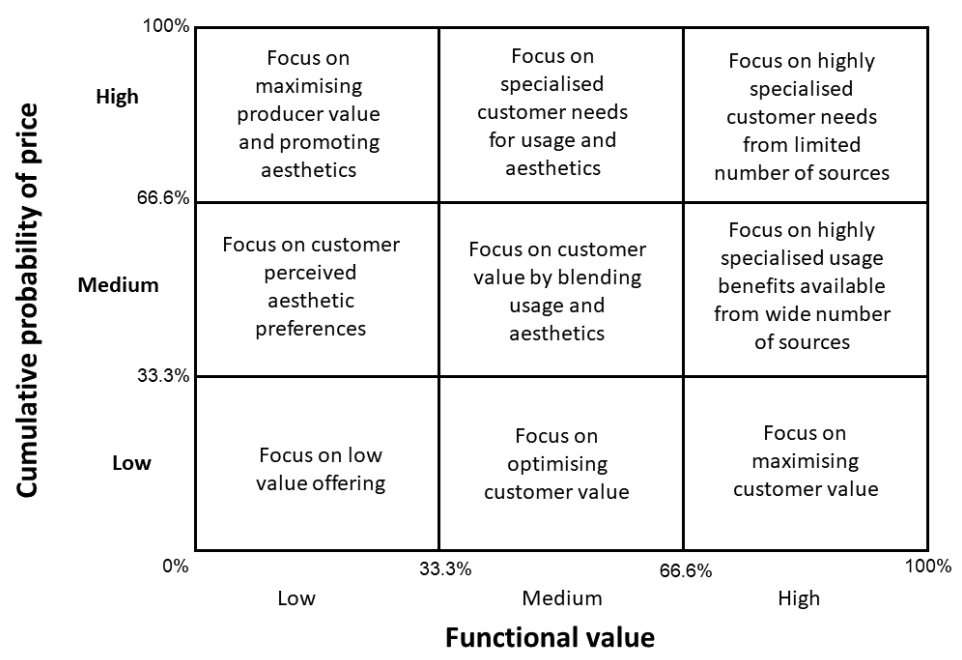

Matrix 1 The focus of a particular VR 


\section{Conclusions}

This paper has addressed a core challenge in VE in that its practice is founded on an idea that mixes measurable and immeasurable concepts. By overcoming this difficulty, this paper links to a longer-term ambition to use $\mathrm{AI}$ as a form of recommendation system.

The paper is also of immediate benefit to VE practitioners as they can now distinguish between functionality that needs cost reduction and functionality that needs value enhancement. This should help the VE community to overturn views that VE is only useful for cost reduction, as well as open doors to a stronger identification with augmented customer value.

Today's VE practitioners can use the value, function, and price method with subsequent incremental invention in a workshop and look to the VR to judge if the suggested improvement really does bring more value forward. This enables VE to engage in cocreation activities where designers and customers collaborate in the act of invention. Matrix 1 offers the means for these two stakeholder groups (i.e., manufacturers and customers) to reflect on what each is trying to achieve.

\section{References}

Argyris, C., 1995. Action Science and Organizational Learning. Journal of Managerial Psychology, Volume 10(6), pp. 20-26

Berawi, M.A., 2006. Distinguishing Concept Types in Function Models During the Act of Innovation. Doctoral's Thesis, Graduate Program, Oxford Brookes University, UK

Berawi, M.A., Berawi, A.R.B., Prajitno, I., Nahry, N., Miraj, P., Abdurachman, Y., Tobing, E., Ivan, A., 2015. Developing Conceptual Design of High Speed Railways using Value Engineering Method: Creating Optimum Project Benefits. International Journal of Technology, Volume 6(4), pp. 670-679

Bytheway, C.W., 2005. Genesis of FAST. Value World, Volume 28(2), pp. 2-7

Chesbrough, H., 2003. Open Innovation: The New Imperative for Creating and Profiting from Technology. Harvard Business School Press, Boston, Mass

Crum, L.W., 1971. Value Engineering; The Organised Search for Value. Longman, Harlow

Dell'Isola, A., 1982. Value Engineering in the Construction Industry, $3^{\text {rd }}$. Edition. Van Nostrand Reinhold Co, New York

Feenberg, A., 2012. Function and Meaning: The Double Aspects of Technology. ISEL Academic Journal of Electronics Telecommunications and Computers, Volume 1(1), http://dx.doi.org/10.34629/ipl.isel.i-ETC.2

Ferré, F., 1995. Philosophy of Technology. University of Georgia Press, Athens, GA

Goodman, M., 1995. Creative Management. Prentice Hall International (UK) Limited, Hemel Hempstead

Heidegger, M., 2001. Being and Time, translate by John Macquarrie and Edward Robinson. Blackwell Publishing Ltd, Oxford

Hermanides, S., Mooi, H.G., Bakker, H., Verbraeck, A., Bosch-Rekveldt, M., 2010. The Influence of Project front-end Management and Project Complexity on Project Success: A Contingency Approach in Project Management Research. In: PMI® Research Conference: Defining the Future of Project Management, Washington, DC, Newtown Square, PA: Project Management Institute. Available Online at https://www.pmi.org/learning/library/project-complexity-front-end-management6470

Hilton, M., 2007. Consumers and the State since the Second World War. The Annals of the American Academy of Political and Social Science, Volume 611. Available Online at 
https://www.jstor.org/stable/25097909

Kaplan, R.S., 1998. Innovation Action Research: Creating New Management Theory and Practice. Journal of Management Accounting Research; Sarasota, Volume 10, pp. 89-118

Kaufman, J.J., 1985. Value Engineering for the Practitioner. North Carolina State University, Raleigh, NC.

Kaufman, J.J., Woodhead, R.M., 2006. Stimulating Innovation in Products and Services. Wiley, Hoboken, NJ

Kelly, J.R., Male, S.P., 1991. The Practice of Value Management: Enhancing Value or Cutting Cost? Royal Institution of Chartered Surveyors, London

King, T.R., 2000. Value Engineering Theory and Practice in Industry. Lawrence D. Miles Value Engineering Reference Center at the University of Wisconsin-Madison, Madison, WI

Kroes, P.A., 2009. Engineering and the Dual Nature of Technical Artefacts. Cambridge Journal of Economics, Volume 34, pp. 51-62

Kroes, P.A., 1998. Technological Explanations: The Relation between Structure and Function of Technological Objects. Technè, Volume 3(3), Available Online at https://scholar.lib.vt.edu/ejournals/SPT/v3n3/KROES.html

Labrecque, L.I., vor dem Esche, J,, Mathwick, C., Novak, T.P. Hofacker, C.F., 2013. Consumer Power: Evolution in the Digital Age. Journal of Interactive Marketing, Volume 27(4), pp. 257-269

Mahner, M., Bunge, M., 2001. Function and Functionalism: A Synthetic Perspective. Philosophy of Science, Volume 68 (1), pp. 75-94

McCuish, J.D., 2002. Value Management and Value Improving Practices. In: Proceedings of SAVE International, USA, pp. 1-16. Available Online at https://pinnacleresults.com/images/PRLLC_Paper_Integrated_VIPs.pdf

McNiff, J., 2017. Action Research: All You Need to Know. Sage Publications Ltd, London

Miles, L.D., 1961. Techniques of Value Analysis and Engineering, $1^{\text {st }}$ Edition. McGraw-Hill Book Co. New York

Miles, L.D., 1972. Techniques of Value Analysis and Engineering, $2^{\text {nd }}$ Edition, McGraw-Hill Book Co. New York

Miles, L.D., 1989. Techniques of Value Analysis and Engineering, $3^{\text {rd }}$ Edition. Miles Value Foundation. The Lawrence D. Miles Value Engineering Reference Center Collection. University of Wisconsin, Madison

Ranjan, K.R., Read, S., 2019. Bringing the Individual into the Co-Creation of Value. Journal of Services Marketing, Volume 33(7), pp. 904-920

Rahman, H.Z., Berawi, M.A., Susantono, B., Miraj, P., Petroceany, J.S., Maya, R., 2018. Investigation of an Operation and Maintenance Framework in the Railway Industry: A Case Study of the Makassar-Parepare. International Journal of Technology, Volume 9(3), pp. 549-557

Rescher, N., 1999. Realistic Pragmatism: An Introduction to Pragmatic Philosophy. State University of New York Press, New York

SAVE International, 2020a. The Value Standard. Available Online at https://cdn.ymaws.com/www.value-

eng.org/resource/resmgr/education/vm_standard_reference_202092.pdf

SAVE International, 2020b. Value Standards. Available Online at https://www.valueeng.org/page/ValueStandards

Searle, J., 1995. The Construction of Social Reality. The Free Press, New York

Seni, D.A., 2005. Function Models: A General Framework for Technological Design. Value World, Volume 28(2), pp. 8-11

Tidd, J., Bessant, J., 2015. Innovation and Entrepreneurship. Wiley, Chichester 
de Ven, A.H.V., Polley, D.E., Garud, R., Venkataraman, S., 2008. The Innovation Journey. The Academy of Management Review, Volume 25(4), pp. 885-887

Woodhead, R.M., 2018. Building A Smarter City. International Journal of Technology, Volume 9 (7), pp. 1509-1517

Woodhead, R.M., Kaufman, J.J., Berawi, M.A., 2004. Is "Drink Beer" a Function? Value World, Volume 27(1), pp. 11-15

Yuliawati, E., Hadiwardoyo, S.P., Susantono, B., Tjahjono, T., 2015. System Dynamics Model for Airport Characterization in Hub-and-Spoke Networks. International Journal of Technology, Volume 6(5), pp. 733-742 